\title{
SERVICIOS DE ATENCIÓN FARMACÉUTICOS
}

\section{Retos fctuales de una profesión cada vez más orientada a las necesidades de los usuarios y al uso más racional de los medicamentos}

Por: Dr. Luis Carlos Monge Bogantes, MSc

Farmacéutico Asistencial, Docente Universitario.

Recibido: 29-11-19

Máster en Atención Farmacéutica Integral.

Aceptado: 4-12-18

\section{(c) $(1) \Theta \theta$}

ए

profesional en farmacia ha estado en una continua y constante evolución a lo largo de muchas décadas, los avances tecnológicos, científicos, industriales, cambios de paradigmas en los que hoy en día la sociedad exige cada vez más de un farmacéutico asistencial (tanto a nivel privado como público) que se comprometa más con las necesidades de los usuarios de los medicamentos.

El asumir un rol más protagónico obliga y responsabiliza directamente al profesional en farmacia a nivel asistencial el brindar servicios de atención farmacéuticas que vayan más orientados al uso responsable de los medicamentos y así poder garantizar una gestión de la farmacoterapia.

Uno de los aspectos más importantes de tomar en cuenta es que el farmacéutico realice una adecuada entrevista a los usuarios de medicamentos, los servicios principalmente van orientados a los pacientes crónicos, polimedicados, con falla terapéutica o que presenten mala adherencia a los tratamientos (incumplimiento). Durante esta primera cita el farmacéutico debe de registrar los datos generales del paciente y documentar todo lo referente a su historia clínica (anamnesis farmacológica). Toda la información recopilada por parte del farmacéutico deberá ser utilizada de forma ética para poder elaborar las estrategias de intervención que se diseñarán según la necesidad específica de cada usuario de los servicios de atención farmacéutica personalizada e integral. El consentimiento informado es un documento de vital importancia que debe siempre estar de por medio en la prestación de servicios asistenciales en atención farmacéutica.

La adherencia terapéutica, es otro aspecto de gran importancia el poder evaluar y determinar ya que este será clave en la determinación de las metodologías y estrategias de intervención farmacéutica que se decidan brindar a cada usuario de medicamento con una falla terapéutica, que tenga un tratamiento crónico y que este polimedicado, ya que los riesgos de esta población son mucho mayores en cuanto al uso adecuado, eficaz y seguro de los medicamentos. Estudios realizados por la Sociedad Española de Farmacia Hospitalaria (SEFH) (cronicidad, 2018) hay unos 18.400 fallecimientos consecuencia de una falta de adherencia y un coste de más de 11.200 millones de euros. Se estima que en Europa la falta de adherencia puede costar hasta 125.000 millones de euros y contribuir a la muerte prematura de 200.000 personas al año.

La consultora IMS Health calcula que el mal uso de los medicamentos supone aproximadamente un $8 \%$ del gasto sanitario del mundo. (Lagos, 2015) El incumplimiento es una de las principales causas de que no se obtengan todos los beneficios esperados de los medicamentos, pueden derivarse complicaciones médicas, mayor gasto sanitario en la atención de complicaciones derivadas al mal uso de los medicamentos. De allí la gran importancia de contar integrado dentro de los sistemas de salud los servicios de atención farmacéutica en los que se evalué y se haga lo posible por mejorar la adherencia terapéutica, se gestione de mejor forma la farmacoterapia de los pacientes, se eviten problemas relacionados con el uso de los medicamentos y se logre así impactar de forma positiva la calidad de vida de las personas.

En Costa Rica, datos de la Caja Costarricense de Seguro Social (SIFA, 2016) en el año 2016 se despacharon y dispensaron en las farmacias de dicha institución pública cerca de 82 millones de recetas, para una población nacional en ese entonces de a penas 4,5 millones de habitantes, se 
conoce que cerca del $50 \%$ de la población no se toma de forma adecuada sus medicamentos.

La utilización de herramientas como los sistemas personalizados de dosificación (SPD), el seguimiento farmacoterapéutico, una adecuada conciliación de la medicación, educación sanitaria (lo que la OMS llama alfabetización sanitaria), promover entre los profesionales de salud y la población en general el uso racional de los medicamentos (por ejemplo, las campañas para evitar el uso de antibióticos de forma irracional). Sin duda alguna la labor del farmacéutico es de vital importancia para integrarse de lleno a brindar soluciones reales a esta problemática, es ahora una buena oportunidad de diferenciarse brindando servicios profesionales acordes a las necesidades que demanda la sociedad actual, involucrar cada vez más a los farmacéuticos con la responsabilidad del seguimiento farmacoterapéutico orientado hacia el individuo, la familia (incluyendo a las redes de cuido o apoyo) y la comunidad.
El valor social de la farmacia comunitaria privada es realmente incalculable, el poder contar con un farmacéutico de confianza que brinde servicios asistenciales personalizados es un valor añadido a la hora de adquirir un medicamento prescrito por el médico, recibir un buen consejo farmacéutico, poder brindar un seguimiento a los pacientes crónicos con mala adherencia, utilizar herramientas que faciliten el uso de los medicamentos y estar siempre dispuesto a brindar información basada en evidencia científicas para mejorar la salud y la calidad de vida de los usuarios de los medicamentos son algunos de lo que se espera de un buen profesional en farmacia.

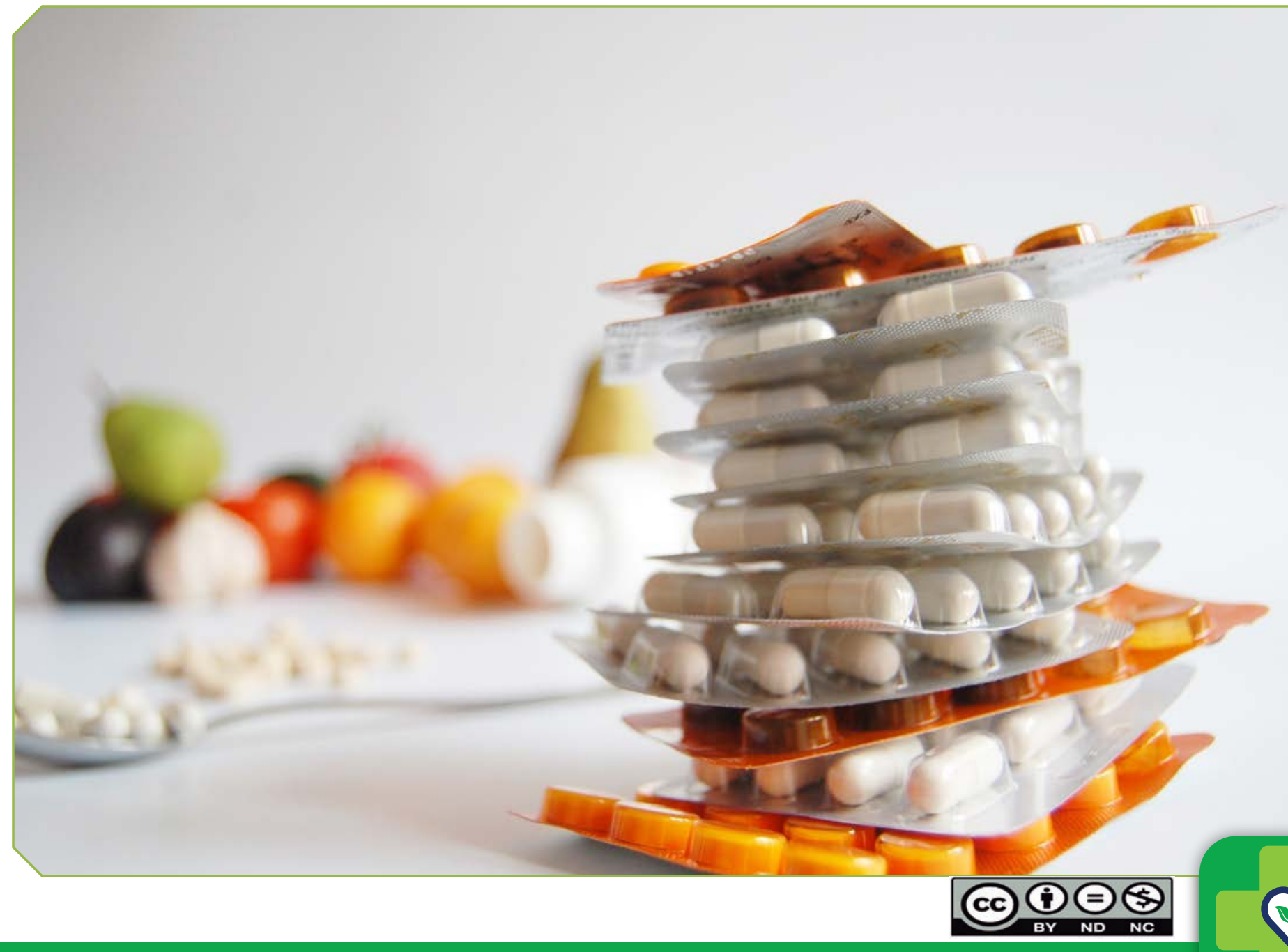

